\title{
MOORING FATIGUE VERIFICATION OF THE WINDCRETE FOR A 15 MW WIND TURBINE
}

\author{
Pau Trubat ${ }^{1}$, Climent Molins ${ }^{1}$, Daniel Alarcon ${ }^{1}$, \\ Valentin Arramounet ${ }^{2}$, Mohammad Youssef Mahfouz ${ }^{3}$ \\ 1UPC-Barcelona-Tech, Barcelona, Catalunya \\ ${ }^{2}$ INNOSEA, Nantes, France \\ ${ }^{3}$ USTUTT, Stuttgart, Germany
}

\section{ABSTRACT}

LCOE reduction in FOWTS is heading to larger wind turbines in order to increase power production and capacity. NREL and DTU have recently developed a $15 \mathrm{MW}$ reference wind turbine, which can be used to validate the platform concepts for the next generation of wind turbines. Increasing the power of wind turbines leads to larger platforms due to the need to withstand the increase of the weight of the Nacelle Rotor Assembly, as well as the increase of the wind forces and pitching moment. Moreover, the larger the turbines and platforms the larger surge/sway and yaw unbalanced forces, which will need to be hold up by the mooring system.

The mooring system has to be designed to balance the wind and wave forces and provide the stiffness needed to the FOWT for a proper behavior. Moreover, the mooring system has to achieve enough reliability to prevent line failure that could lead to a chain reaction within a floating wind farm, and thus huge loses. Then, a complete and detailed fatigue analysis should be performed in order to guarantee the performance of the FOWT during its service life.

Within the CoReWind EU-2020 project, the Windcrete platform is upscaled to withstand the new EIA $15 \mathrm{MW}$ reference wind turbine. As concrete is used as a main material, the mass and inertia are larger than steel counterpart which leads to stiffer and more loaded mooring system. In this paper, the fatigue analysis of the Windcrete mooring system is assessed and compared using different methods.

Keywords: moorings, fatigue, WindCrete, dynamic, quasidynamic, EIA 15MW reference wind turbine.

\section{NOMENCLATURE}

$\begin{array}{ll}\text { CM } & \text { Center of Mass } \\ \text { DOF } & \text { Degree Of Freedom } \\ \text { FOWT } & \text { Floating Offshore Wind Turbine } \\ \text { MSL } & \text { Mean Sea Level } \\ \text { RNA } & \text { Rotor Nacelle Assembly }\end{array}$

\section{INTRODUCTION}

The upcoming new turbines for offshore wind are becoming larger and powerful, achieving the 10MW for the MHI Vestas [1] and the Haliade-X to $12 \mathrm{MW}$ [2]. Moreover, recently the IEA presented a new $15 \mathrm{MW}$ reference wind turbine[3], which defines the next target for the actual wind turbines manufacturers.

The increase of the power of the wind turbines will suppose an increase of the weight of the RNA and the thrust forces that the floating platforms have to withstand. Then, larger and more massive platforms are expected to be designed in order to allow the support of those wind turbines. The nature of floating platforms implies the necessity of a mooring system to restrain the free motion DOFs, the surge/sway and the yaw. This mooring system will have to balance the mean thrust wind and drift wave forces as well as carry the dynamic tension due to the stochastic wind and wave forces during the lifespan of the FOWT. Therefore, a fatigue analysis of the mooring system is a key factor to ensure the reliability of the mooring lines.

The fatigue analysis of the mooring system is mainly based on a damage accumulation procedure [4], the Palmgren-Miner's linear addition rule, by assessing the damage for each cycle by the S-N curves or T-N curves. S-N curves are based in the stress range while T-N curves consider the ratio of tension range to reference breaking.

Within the CoReWind project of the EU 2020 Horizon program the WindCrete platform is upscaled to support the IEA 
$15 \mathrm{MW}$ reference wind turbine. As concrete is used as a main material, the mass and inertia are larger than steel counterpart which leads to the need of a stiffer mooring system to achieve the needed restoring forces/moment for the surge/sway and yaw motions.

In this paper the fatigue analysis for three mooring system predesigns for the WindCrete carrying the IEA-15 MW reference wind turbine is presented. The study assesses the fatigue accounting for different fairlead positions. Moreover, the fatigue analysis is performed using three different mooring analysis techniques, the dynamic approach [5]-[8], the quasi-dynamic approach [9] and the quasi-static approach [10].

\section{WINDCRETE PLATFORM AND MODEL}

The WindCrete platform of this study [11], [12] is dimensioned to support the IEA-15MW reference wind turbine [3] and withstand wind and waves loads whilst ensuring good performance of the turbine in Power Production state in the Gran Canaria Island location [13]. A sketch of the WindCrete platform for the $15 \mathrm{MW}$ WT is shown in Figure 1. The structure has a tower $135 \mathrm{~m}$ tall, from the MSL, and a draft of $155 \mathrm{~m}$. The buoy is composed of hemisphere at the bottom of the buoy followed by a cylindrical section of $135.7 \mathrm{~m}$ and a tapered section of $10 \mathrm{~m}$ between the buoy and the tower that starts at the MSL. The cylinder and the hemisphere have a diameter of $18.6 \mathrm{~m}$ and a thickness of $0.5 \mathrm{~m}$ and the tapered section has a lower diameter of $18.6 \mathrm{~m}$ and an upper diameter of $13.2 \mathrm{~m}$ at MSL with a constant thickness of $0.5 \mathrm{~m}$. The tower starts at the MSL and has a top diameter of $6.5 \mathrm{~m}$ at the yaw bearing and a mean thickness of $0.4 \mathrm{~m}$. The ballast added to achieve a suitable Pitch/Roll hydrostatic stiffness has a weight of $25.07 \mathrm{kTonnes}$ and consists on an aggregate with a specific weight of $25 \mathrm{kN} / \mathrm{m}^{3}$ located at the bottom of the cylinder. The main properties of the platform are summarized in Table 1. The inertia terms of Table 1 are assessed from the CM and include the RNA. The hydrostatic stiffness values also account for the weight. More detailed definition of the WindCrete for the IEA-15MW can be found in [14].

The WindCrete is modelled by OpenFAST, an aero-servohydro-elastic simulation tool [15]. The properties of WindCrete are reflected in the model by adjusting all the relevant input parameters spread across the different FAST modules. The aerodynamics module accounts for tip and hub losses as well as for the tower shadow. Hydrodynamics are determined from a hydrostatic stiffness matrix and wave loads are computed using PF solution of the substructure for the first and second order wave forces. Drag forces are accounted by the viscous terms of the Morison equation. The Table 2 shows the Morison hydrodynamic coefficients used in FAST.

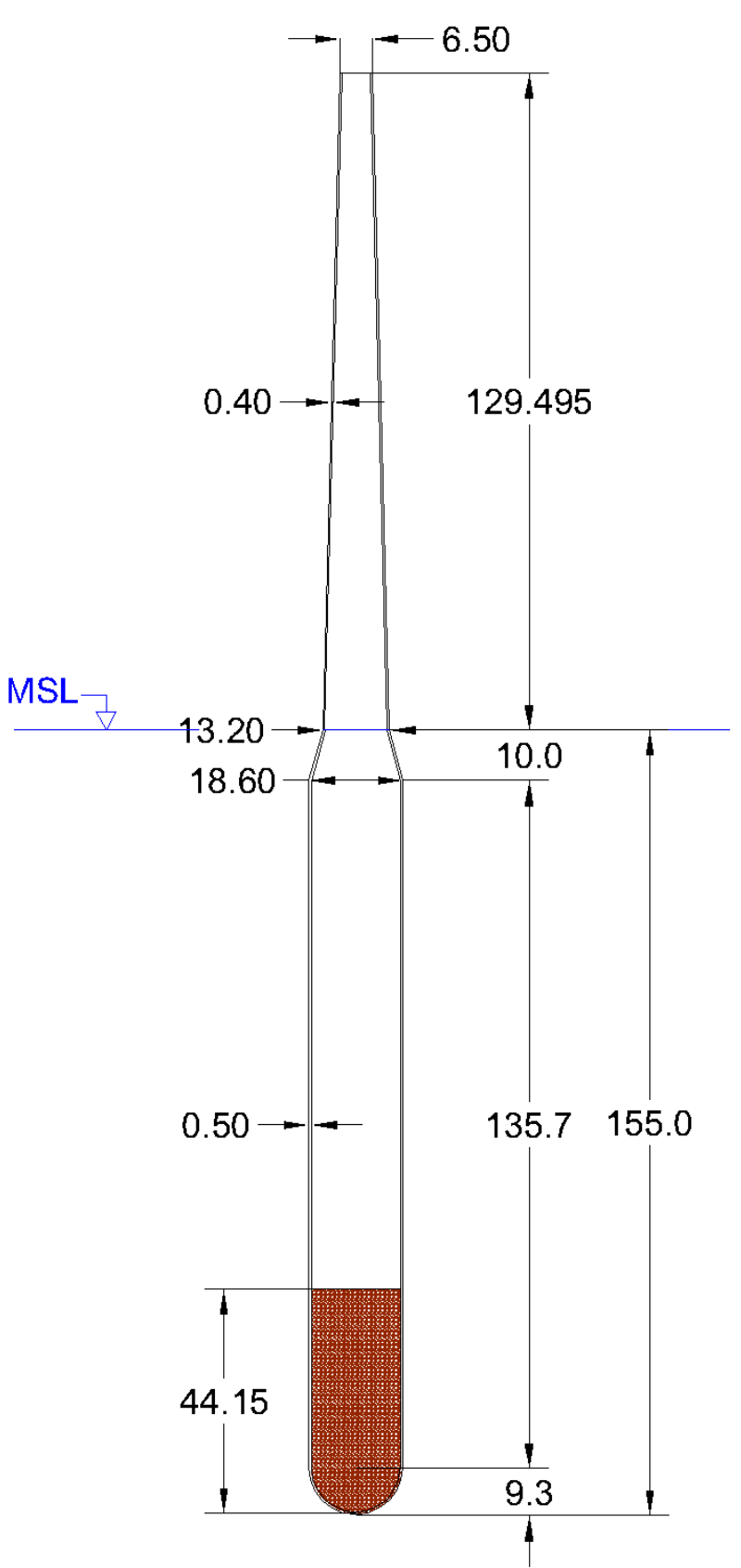

FIGURE 1: WINDCRETE SKETCH AND MAIN DIMENSIONS IN METERS [14] 
TABLE 1: WINDCRETE MAIN PROPERTIES

\begin{tabular}{|c|c|}
\hline Displaced volume $\left[\mathrm{m}^{3}\right]$ & $4.054 \mathrm{e}+04$ \\
\hline Draft [m] & 155 \\
\hline Concrete mass [kg] & $1.474 \mathrm{e}+07$ \\
\hline Ballast [kg] & $2.507 \mathrm{e}+07$ \\
\hline Wind turbine mass [kg] & $8.211 \mathrm{e}+05$ \\
\hline CM [m] & -93.72 \\
\hline CB [m] & -77.29 \\
\hline Total Mass [kg] & $4.063 \mathrm{e}+07$ \\
\hline $\mathrm{I}_{44}\left[\mathrm{~kg} \cdot \mathrm{m}^{2}\right]$ & $1.986 \mathrm{e}+11$ \\
\hline $\mathrm{I}_{55}\left[\mathrm{~kg} \cdot \mathrm{m}^{2}\right]$ & $1.987 \mathrm{e}+11$ \\
\hline$I_{66}\left[\mathrm{~kg} \cdot \mathrm{m}^{2}\right]$ & $1.947 \mathrm{e}+09$ \\
\hline $\mathrm{C}_{33}[\mathrm{~N} / \mathrm{m}]$ & $1.376 \mathrm{e}+06$ \\
\hline $\mathrm{C}_{44}[\mathrm{~N} \cdot \mathrm{m} / \mathrm{rad}]$ & $6.713 \mathrm{e}+09$ \\
\hline $\mathrm{C}_{55}[\mathrm{~N} \cdot \mathrm{m} / \mathrm{rad}]$ & $6.713 \mathrm{e}+09$ \\
\hline
\end{tabular}

TABLE 2: FAST MORISON HYDRODYNAMIC COEFICIENTS

\begin{tabular}{|l|l|} 
& Cd \\
\hline Base (Axial direction) & 0.2 \\
\hline Cylinder & 0.7 \\
\hline Transition piece & 0.7 \\
\hline
\end{tabular}

\section{SITE LOCATION}

The location chosen for the fatigue study is in the southeast of Gran Canaria Island in Spain, shown in Figure 2, with a depth of $200 \mathrm{~m}$.

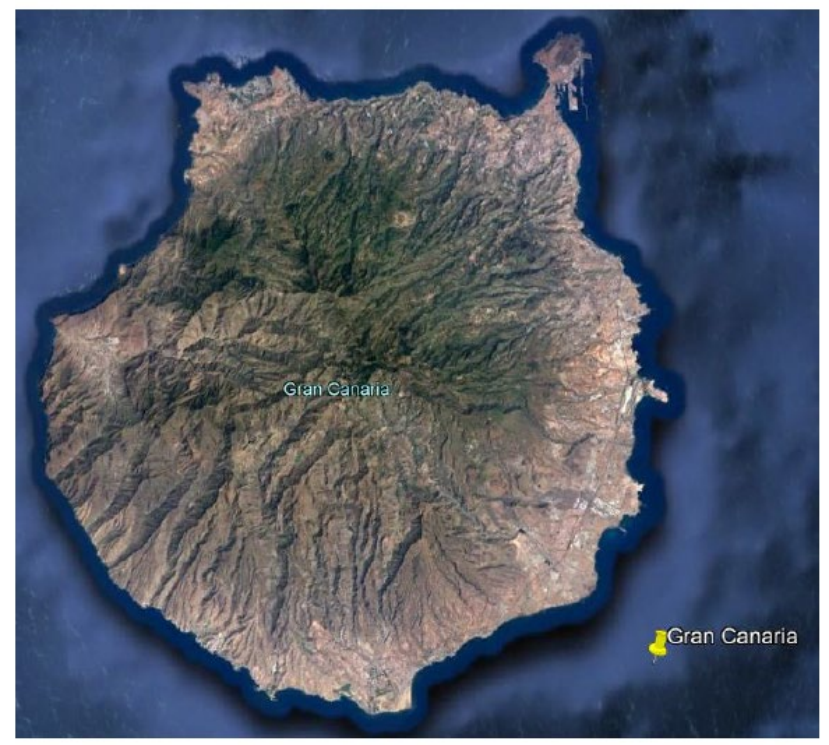

FIGURE 2: GRAN CANARIA DITE LOCATION
The wind and wave data are considered to be uni-directional to reduce the number of load cases to study. The Table 3 shows the joint probability distribution of the significant wave and wind velocity at $10 \mathrm{~m}$ height. The winds are discretized in different bins and the significant wave height are discretized each $1 \mathrm{~m}$ from 0.5 to $3.5 \mathrm{~m}$. The values used are based on de data of design basis of CoReWind project [13].

TABLE 3: WIND-WAVE PROBABILITY DISTRIBUTION IN \%

\begin{tabular}{|c|l|l|l|l|l|}
\hline \multicolumn{3}{|c|}{ Wind/Wave } & \multicolumn{4}{|c|}{ Significant Wave Height Hs [m] } \\
\cline { 3 - 6 } \multicolumn{2}{|c|}{} & $\mathbf{0 . 5}$ & $\mathbf{1 . 5}$ & $\mathbf{2 . 5}$ & $\mathbf{3 . 5}$ \\
\hline \multirow{3}{*}{} & $\mathbf{1 . 4}$ & 1.04 & 1.51 & 0.19 & 0.01 \\
\cline { 2 - 6 } & $\mathbf{4 . 1}$ & 15.61 & 22.84 & 2.60 & 0.12 \\
\cline { 2 - 6 } & $\mathbf{9 . 6}$ & 17.02 & 24.36 & 2.98 & 0.15 \\
\cline { 2 - 6 } & $\mathbf{1 5 . 0}$ & 4.07 & 5.37 & 0.75 & 0.03 \\
\cline { 2 - 6 } & $\mathbf{2 0 . 5}$ & 0.46 & 0.67 & 0.13 & 0.00 \\
\cline { 2 - 6 } & $\mathbf{2 6 . 0}$ & 0.03 & 0.05 & 0.01 & 0.00 \\
\cline { 2 - 6 } & $\mathbf{2 8 . 7}$ & 0.00 & 0.00 & 0.00 & 0.00 \\
\hline \multirow{2}{*}{}
\end{tabular}

\section{MOORING SYSTEM}

In this paper, three different mooring systems are designed varying the fairlead depth. Fairleads closer to the $\mathrm{CM}$ of the platform will be subjected mainly to the platform translation motions, whereas fairlead location far from the CM will have larger motions due to the coupling between the pitch and surge motions. However, fairlead located near the MSL will reduce the pitch of the platform, which may be beneficial for the FOWT behavior. The fairlead locations chosen are at a depth of 0,45 and $90 \mathrm{~m}$ and each case is identified with the following names $\mathrm{C} 0, \mathrm{C} 45$ and $\mathrm{C} 90$ respectively.

The mooring system for each case is designed to ensure station-keeping of the floating platform with a surge and yaw natural periods around $100 \mathrm{~s}$ and $12 \mathrm{~s}$ respectively and no vertical reaction at the anchor. The mooring system consists of three catenary lines spaced $120^{\circ}$ apart with a delta line connection to the buoy to provide yaw stiffness to the system. For simplicity all lines are composed with the same chain, which properties are presented in Table 4.

TABLE 4: WINDCRETE MOORING SYSTEM MAIN PROPERTIES

\begin{tabular}{lccc}
\hline & C0 & $\mathbf{C 4 5}$ & $\mathbf{C 9 0}$ \\
\hline Radius to anchor [m] & 770 & 665 & 600 \\
\hline Chain line length [m] & 760 & 642 & 565 \\
\hline Delta line length [m] & 50 & 50 & 50 \\
\hline $\begin{array}{l}\text { Chain nominal } \\
\text { diameter [mm] }\end{array}$ & 160 & 160 & 160 \\
\hline $\begin{array}{l}\text { Chain apparent diameter } \\
\text { [mm] }\end{array}$ & 301 & 301 & 301 \\
\hline Chain wet weight [N/m] & $4.8 \mathrm{e}+03$ & $4.8 \mathrm{e}+03$ & $4.8 \mathrm{e}+03$ \\
\hline Chain Axial stiffness [N] & $2.3 \mathrm{e}+9$ & $2.3 \mathrm{e}+9$ & $2.3 \mathrm{e}+9$ \\
\hline
\end{tabular}


The mooring system is placed such as the mooring line 1 is pointing to the $\mathrm{x}$ axis. Then, the anchors of mooring lines 2 and 3 have the $x$ coordinate positive, as shown in Figure 3 . There are three fairleads at the platform, one per two lines. In order to differentiate the tension of each line, the tension of each fairlead are numbered with the number $\mathrm{XY}$, where $\mathrm{X}$ is the number of the line, and $\mathrm{Y}$ is the number of the fairlead as shown in Figure 3.

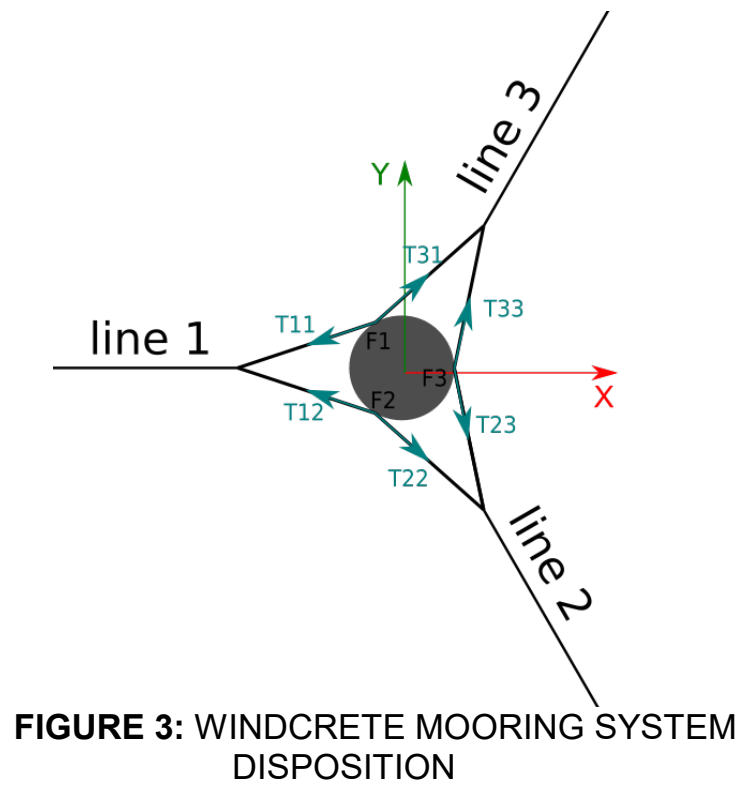

\section{MOORING MODELS}

Currently there are two different models to assess the mooring behavior and its interaction with the platform. These models are the quasi-static mooring model and the dynamic mooring model. In both models, the fairlead motion is applied to the mooring system and the response of the lines are applied to the platform based on the forces at the fairleads. The difference between the models is that the quasi-static model is based on the statics of the mooring system whereas the dynamic model accounts for the dynamics of the line. The dynamic mooring model performs a higher accuracy assessment but quasi-static approach is much more computationally efficient due to removal of a significant number of degrees of freedom.

Recently a new approach called quasi-dynamic mooring model based was presented by Trubat in [9]. This new approach is based on the quasi-static solution but including an estimation of the drag and inertia forces on the line which better approaches the mooring dynamics with a very limited computational cost.

A brief description of each model can be found following:

\section{Dynamic mooring model}

The mooring dynamic model solves the dynamic equation of a line, Eq. (1), by using either the lumped mass method, the finite differences method or the finite element method. The lines are divided in a number of elements and the external forces and internal reactions are applied at the discretized elements. Finally, the kinematics of the line are assessed at each time step resolving the second newton law by numerical integration methods.

$$
\rho A \frac{\partial^{2}}{\partial t^{2}} r=\frac{\partial}{\partial s} T+f_{e}
$$

Where $\rho$ is the material density of the line, $A$ is the cross section area of the line, $r$ is the position of the centerline of the line, $t$ is the time, $s$ is the arclength parameter, $\mathrm{T}$ is the line tension tangent to the line and $f_{e}$ are the external forces.

\section{Quasi-static mooring model}

The quasi-static mooring model is based on the static solution of the line subjected only to the submerged weight and the constraints of the seabed.

The catenary equation can be solved accounting for the axial stiffness of the line by the Eq. (2).

$$
\begin{aligned}
x-x_{0}=\frac{T_{H}}{\omega}[\ln ( & \left.\frac{1}{\cos (\phi)}+\tan (\phi)\right) \\
& \left.-\ln \left(\frac{1}{\cos \left(\phi_{0}\right)}+\tan \left(\phi_{0}\right)\right)\right] \\
& \quad+\frac{T_{H}}{E A} l \\
z-z_{0}= & \frac{T_{H}}{\omega}\left[\frac{1}{\cos (\phi)}-\frac{1}{\cos \left(\phi_{0}\right)}\right]+\frac{1}{2} \frac{\omega}{E A} l^{2}
\end{aligned}
$$

Where $x, z$ are the in plane horizontal and vertical positions, $T_{H}$ is the horizontal component of the line tension, $\omega$ is the wet weight per meter length of the line, $\phi$ is the angel between the vertical and horizontal tension, $l$ is the length of the line and $E A$ is the axial stiffness of the line.

\section{Quasi-dynamic mooring model.}

The quasi-dynamic mooring model is based on the static solution of the quasi-static mooring model but the tension at the fairlead is updated by a quasi-dynamic factor $\left(k_{Q D}\right)$, shown in Eq. (3), which accounts the hydrodynamic and inertia forces. These forces in the vertical direction modify the wet weight of the line to an updated equivalent wet weight.

$$
\begin{gathered}
T_{Q D}=k_{Q D} T_{Q S} \\
k_{Q D}=\frac{\int_{s_{0}}^{l}\left(\boldsymbol{f}_{w}+\boldsymbol{f}_{H D}-\boldsymbol{f}_{I}\right) \cdot \boldsymbol{k} d s}{\int_{s_{0}}^{l} \boldsymbol{f}_{w} \cdot \boldsymbol{k} d s} \geq 0
\end{gathered}
$$

Where $T_{Q D}$ and $T_{Q S}$ are the line tensions for the quasidynamic and quasi-static models respectively, $\boldsymbol{f}_{w}, \boldsymbol{f}_{H D}, \boldsymbol{f}_{I}$ are the weight, hydro dynamic and inertia distributed forces along the line, $\boldsymbol{k}$ is the unitary vector pointing against the gravity.

\section{SIMULATION PROCEDURE}

The simulations are performed by OpenFAST model with 6 different seeds of 600 seconds each for every case set in Table 3.

The reference system is such that the intersection of the vertical axis of the WindCrete platform with the water plane area is the $[0,0,0]$ position. Moreover, the wind and waves directions are set to the $\mathrm{x}$ degree of freedom.

The mooring model is simulated using the MoorDyn OpenFAST dynamic module. Then, in order to compare the 
simulations with the different mooring models, the quasi-static and quasi-dynamic models are assessed from the imposed motion of the platform from the FAST simulations. This procedure, does not accounts for the coupling between the mooring models and the FOWT model, but allows compare them easily.

The fatigue analysis is performed using DNV-GL mooring standard [9] and the rainflow counting to obtain the tension range. The damage of the mooring in a state $\mathrm{i}\left(d_{i}\right)$ line is assessed by Eq.(11).

$$
d_{i}=\frac{n_{i}}{a_{D}} E\left[S_{i}^{m}\right]
$$

Where, $n_{i}$ is the number of stress cycles, $a_{D}$ is the intercept parameter of the $\mathrm{S}-\mathrm{N}$ curve, $\mathrm{m}$ is the slope of the $\mathrm{S}-\mathrm{N}$ curve, and $E\left[S_{i}^{m}\right]$ is the expected value of the nominal stress ranges raised to the power $m$ in the state $i$.

Assuming that the mooring line is a studless chain, the $a_{D}$ is set to $6.0 \mathrm{E}+10$ and $\mathrm{m}$ is set to 3 . In this analysis, the corrosion allowance is not taken into account.

\section{OVERVIEW OF THE RESULTS}

In this section an overview of the platform motion and behavior is presented. The Figure 4 shows the surge(a), pitch(b) and wind(c) PSDs functions for a 3600s simulation of the WindCrete platform for the C90 case. The simulation is based on the DLC1.6 with the 50 year return period sea state of $H_{S}$ of $5.11 \mathrm{~m}$ and $T_{P}$ of $9 \mathrm{~s}$ and a rated wind speed $(\mathrm{U})$ of $10.5 \mathrm{~m} / \mathrm{s}$. The Figure 4 shows that the motions of the WindCrete are mainly found on the low frequency region for both surge and pitch. Moreover, comparing with the frequency range corresponding to the wave first order loads, the motions are much lower. Then, the main source of the low frequency loads is the wind forces.

The results of this analysis show that the use of a $15 \mathrm{MW}$ FOWT implies that the wind forces affect much more the movements than the wave forces. Then, it is expected that the mooring system will be excited in this frequency range, and its own dynamics will be less important.

a)

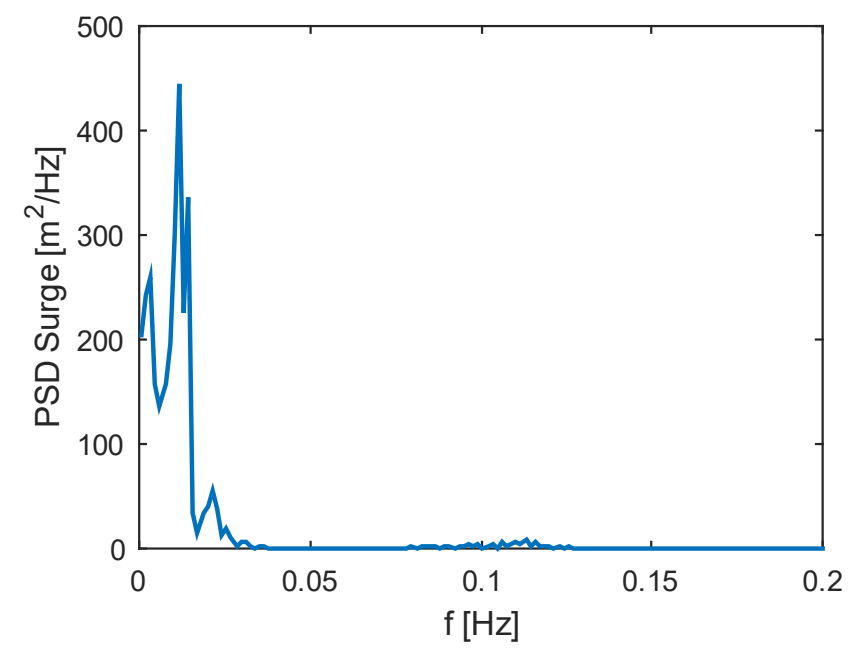

b)

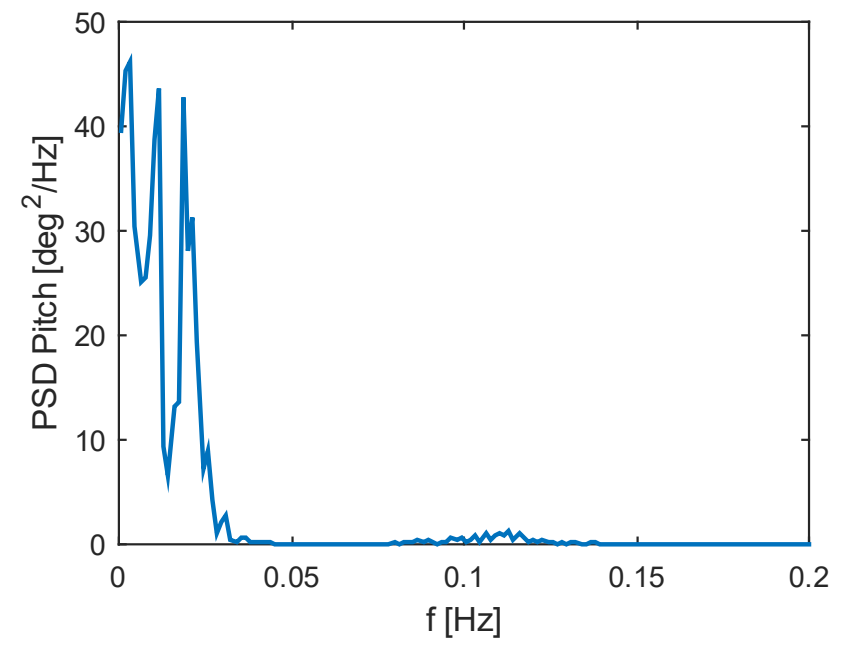

c)

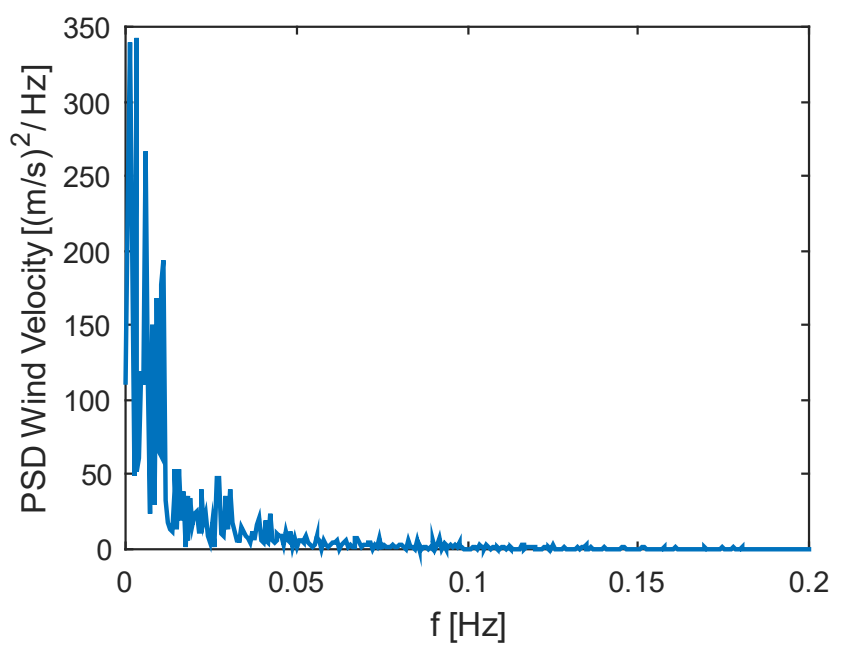

FIGURE 4: PSD FUNCTIONS OF SURGE (a), PITCH(b) AND WIND(c) FOR DLC1.6 WITH A $H_{S}=5.11 m, T_{p}=9 s$ AND $U=$ $10.5 \mathrm{~m} / \mathrm{s}$

\section{MOORING RESULTS}

The comparison of the simulations shows the good behavior of the quasi-static and quasi-dynamic models compared with the dynamic simulations. Figure 5 shows the comparison of the tension for the three mooring models in the load case with a $H_{s}$ of $2.5 \mathrm{~m}$ and a mean wind speed of $9.6 \mathrm{~m}$ for the $\mathrm{C} 0(\mathrm{a}), \mathrm{C} 45(\mathrm{~b})$ and $\mathrm{C} 90(\mathrm{c})$. 
a)

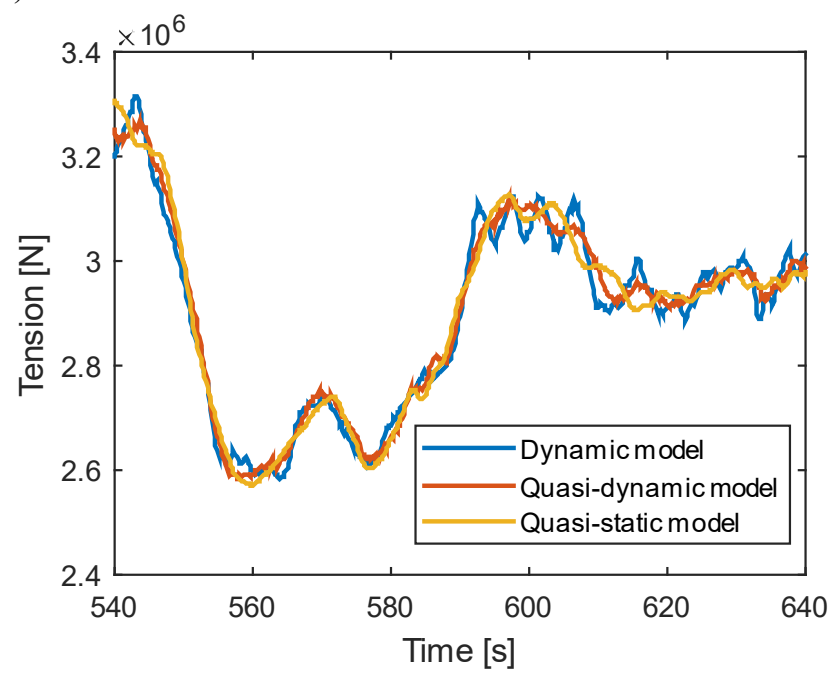

b)

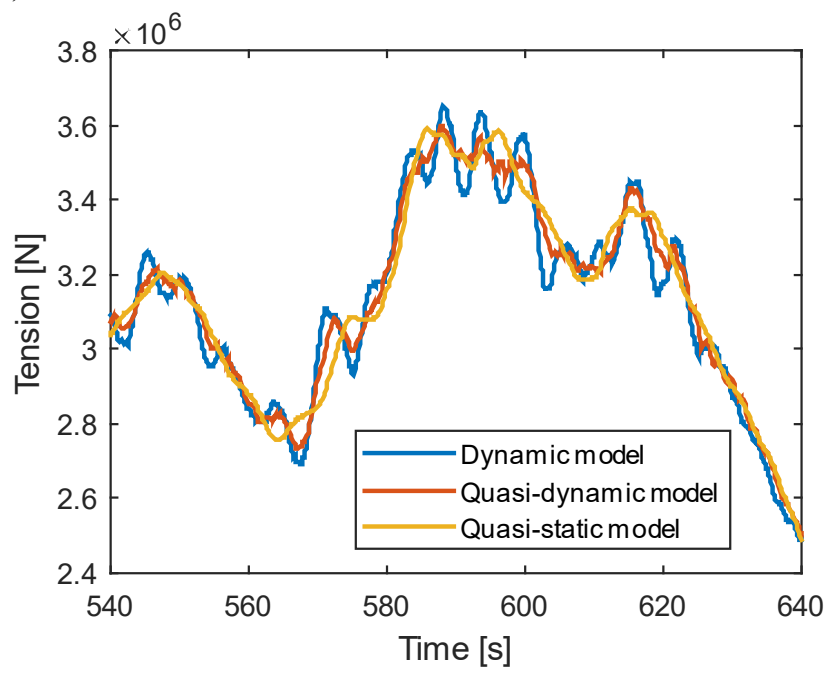

c)

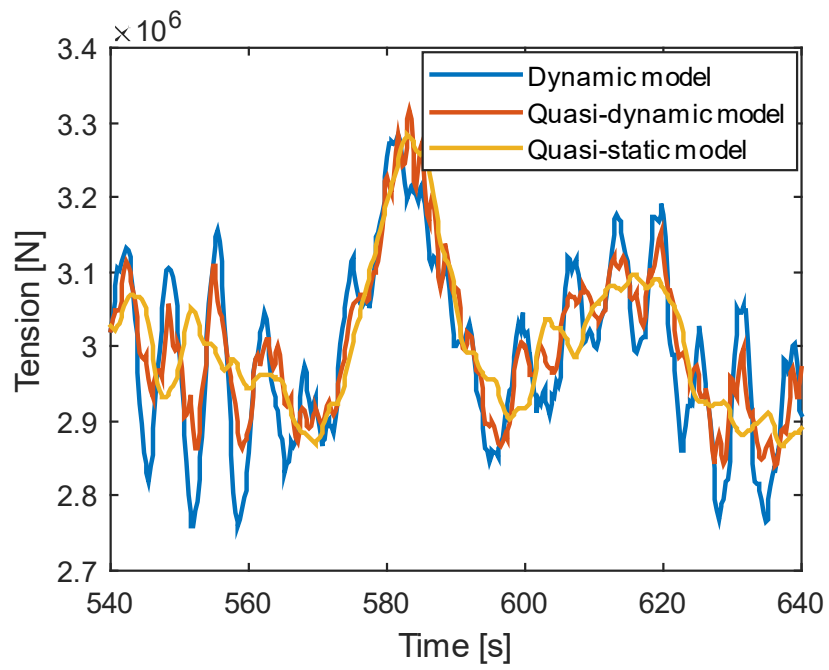

FIGURE 5: TENSION COMPARISON BETWEEN THE T11 OF THE THREE MODELS FOR THE C90(A), C45(B) AND C0(C) CASES
The quasi-dynamic and quasi-static models fit very well the low frequency behavior of the tension, as the mean tension is well captured (Figure 5). For the C90 case the differences between the models are very limited because the coupling between the pitch and surge motions of the fairleads is very low and the position of the fairleads is not affected by the wave loads. As the fairlead goes up, for the cases $\mathrm{C} 45$ and $\mathrm{C} 0$, the coupling of the pitch and surge is noticed by larger tension amplitudes for periods around 10 seconds. In these cases, the quasi-static model is not able to simulate the amplitudes at those frequencies and in some cases can also fall out of phase. However, the quasidynamic model, captures the instant tension better than the quasi-static approach. In this case, the use of this simplified model allows to capture the right phase of the tension but the amplitudes are underestimated. It has to be stated that each line of the mooring system is composed by three segments which likewise induce larger motions normal to the longitudinal plane of the main line inducing horizontal forces that the quasidynamic model does not capture. The Figure 6 shows the PSD comparison of the T11 for the dynamic, quasi-dynamic and the quasi-static model. The figure shows the good agreement between the three models in the low frequency range which is also the most powerful. In the wave frequency range, the quasistatic model presents the lower energy and the quasi-dynamic also underestimates the energy of the mooring response but is much closer to the full dynamic results. From this previous analysis is expected that the design life will be on the same order of magnitude for the three models because the larger tension ranges will come from the low frequency motions. However, the quasi-static approach will present the larger life span due to the underprediction of the tension increments in the wave frequency range in particular for the $\mathrm{C} 0$ case.

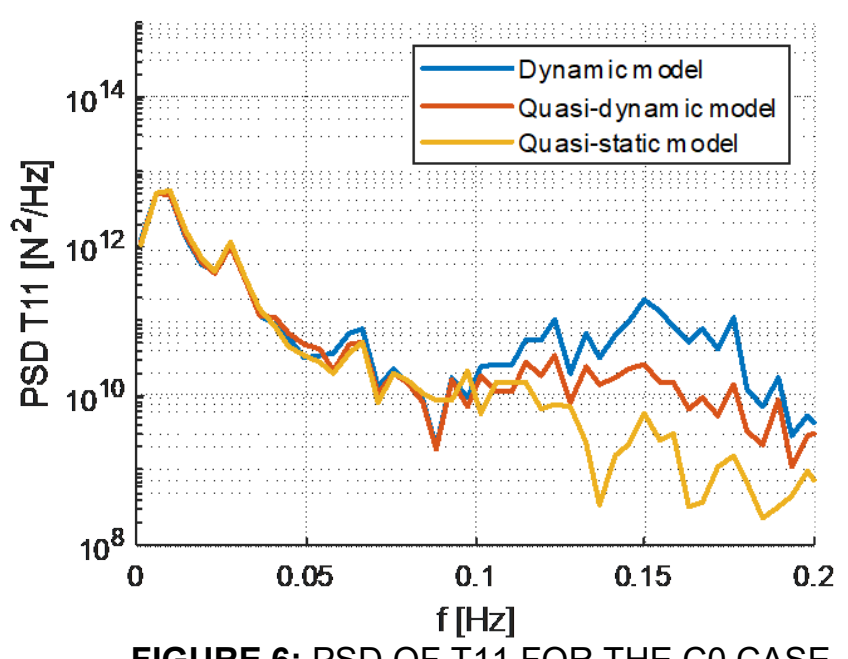

\section{FAIRLEAD POSITION FATIGUE ASSESSMENT}

As previously seen, the main differences between the $\mathrm{C} 0$, C45 and C90 are the pitch and surge coupling motion at the fairleads that increase with the distance from the CM. However, 
due to the dimensions and properties of the platform, the main source of the variation of the line tension is in the low frequency range, where the moorings are more compliant, due to the second order wave forces and, mainly, the wind. Then, from the point of view of the mooring design, moving away the fairlead locations from the $\mathrm{CM}$ of the platform will not present an important reduction of the fatigue life and at the same time would help to reduce the mean tilt of the platform. The Table 5 shows the one year damage of the different mooring lines at each fairlead for the different approaches, the dynamic model (D), the quasidynamic model (QD) and the quasi-static model (QS).

TABLE 5: 1 YEAR DAMAGE FOR THE DIFFERENT CASES

\begin{tabular}{l|l|l|l|l|l|l|l} 
& & T11 & T12 & T22 & T23 & T33 & T31 \\
\hline \multirow{4}{*}{ C0 } & D & 0.0181 & 0.0297 & 0.0058 & 0.0072 & 0.0065 & 0.0084 \\
\cline { 2 - 7 } & QD & 0.0137 & 0.0229 & 0.0045 & 0.0061 & 0.0049 & 0.0068 \\
\cline { 2 - 7 } & QS & 0.0118 & 0.0205 & 0.0041 & 0.0058 & 0.0044 & 0.0068 \\
\hline \multirow{4}{*}{ C45 } & D & 0.0274 & 0.0301 & 0.0082 & 0.0112 & 0.0088 & 0.0096 \\
\cline { 2 - 8 } & QD & 0.0242 & 0.0260 & 0.0072 & 0.0104 & 0.0079 & 0.0090 \\
\cline { 2 - 8 } & QS & 0.0233 & 0.0254 & 0.0069 & 0.0103 & 0.0078 & 0.0090 \\
\hline \multirow{3}{*}{ C90 } & D & 0.0410 & 0.0624 & 0.0071 & 0.0077 & 0.0066 & 0.0075 \\
\cline { 2 - 7 } & QD & 0.0388 & 0.0584 & 0.0071 & 0.0077 & 0.0060 & 0.0074 \\
\cline { 2 - 7 } & QS & 0.0393 & 0.0604 & 0.0071 & 0.0078 & 0.0061 & 0.0077
\end{tabular}

The results of the table 5 are shown in Figure 7 which compares the damage between the fairlead position for the dynamic mooring model simulations. It can be seen that the damage of the fairleads of the line aligned with the wind and wave direction (T11 and T12) are from 3 to 4 times larger than the damage of the not aligned lines.

On the other hand, the figure 7 also shows that the damage of the $\mathrm{C} 90$ case is larger than the damage of the $\mathrm{C} 0$ case. This difference was not expected because the wave frequency motions increases the mooring tension amplitudes. One possible explanation for this behaviour is the difference between the actual stiffness of both $\mathrm{C} 0$ and $\mathrm{C} 90$ mooring systems. The natural period in surge of the $\mathrm{C} 90$ is about 80 s, while the surge natural period is of about $125 \mathrm{~s}$ for the $\mathrm{C} 0$ case. This difference changes the number of tension cycles in the low frequency range which increases the damage for the $\mathrm{C} 90$ case.

The Figure 8 shows the difference of the damage between the mooring models for the $\mathrm{T} 11$ for the cases $\mathrm{C} 0, \mathrm{C} 45$ and $\mathrm{C} 90$. The figure shows clearly that the quasi-static and quasi-dynamic models work well for the $\mathrm{C} 90$ case, because the mooring tension variation comes mainly from the low frequency range. For the $\mathrm{C} 0$ case, the differences between models are larger due to the influence of the wave frequency motions as also displayed in Figure 6. However, the quasi-dynamic model improves the results of the quasi-static model.

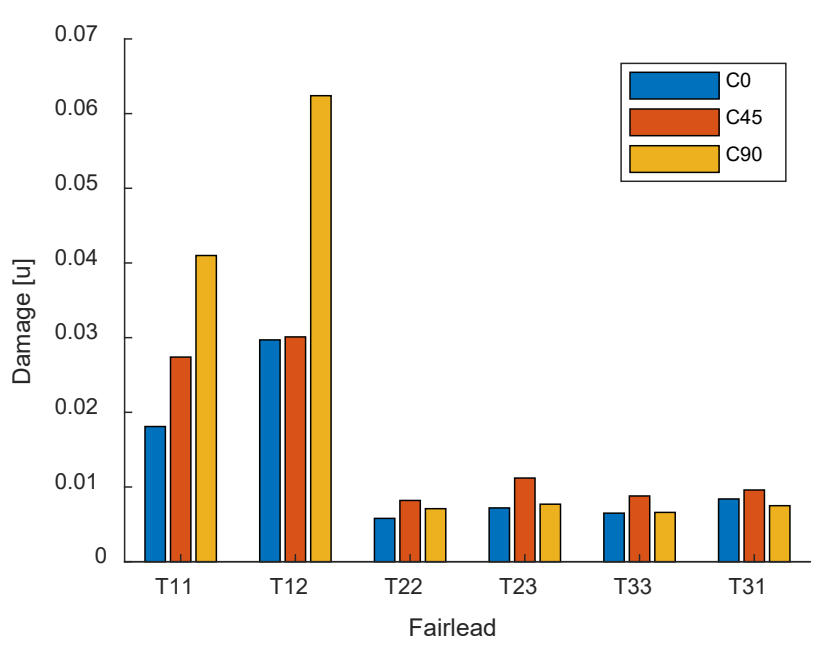

FIGURE 7: DAMAGE COMPARISON BETWEEN FAIRLEAD LOCATION

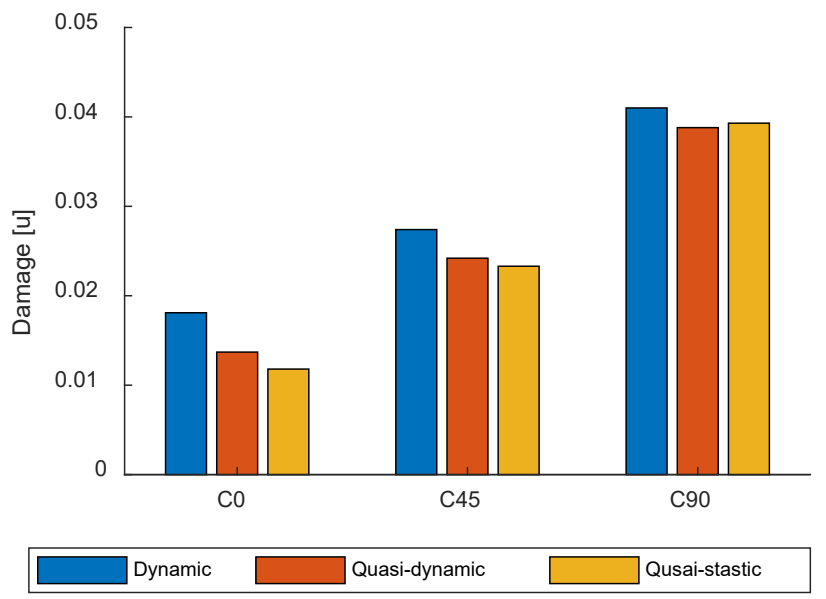

\section{FIGURE 8: DAMAGE COMPARISON BETWEEN} MOORING MODELS OF T11

If the pitch response of the platform is compared, the higher fairlead position the less pitching of the platform. The figure 9, shows the comparison of the PSD of the Pitch for the C0, C45 and $\mathrm{C} 90$ cases and shows the clear reduction of the amplitude at the pitch DOF. Moreover, the increase of the height of the fairleads increase the stiffness in the pitch rotation DOF. 


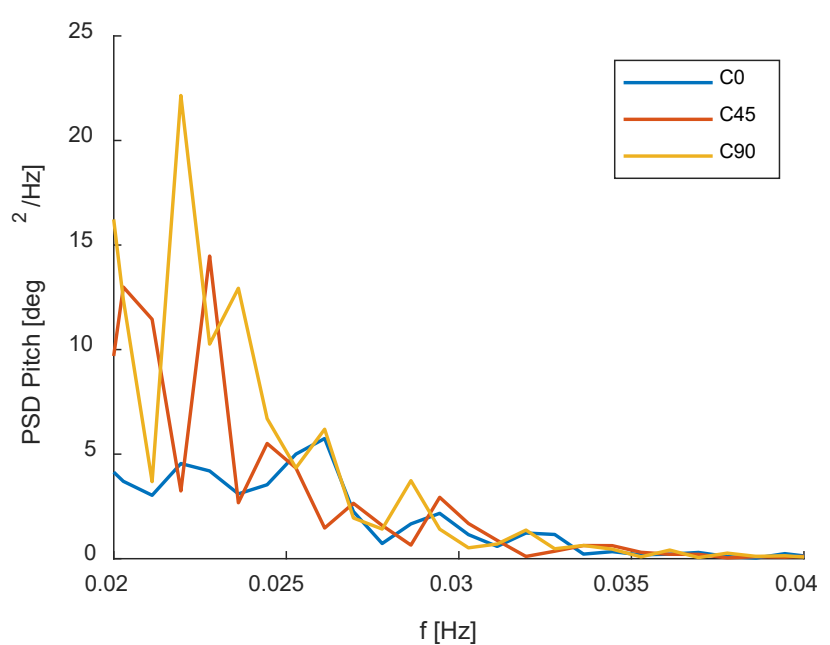

FIGURE 9: PSD COMPARISON OF PITCH ROTATION AT THE PITCH NATURAL FREQUENCY REGION

\section{CONCLUSIONS}

In this paper the fatigue analysis of the response of three mooring systems for the WindCrete platform supporting the IEA-15MW reference wind turbine is presented.

The main difference on the mooring systems is the fairlead depth location, which implies the modification of the line length and radius to anchor.

The simulations of the FOWT response show clearly the large influence of the wind forces on the fatigue life of the mooring system. The wind forces affect mainly in the low frequency range and imply larger tension ranges than the loads from the wave frequency range. However, if the wave frequency range motions are underestimated by using a quasi-static mooring approach, the damage can be under-predicted as much as $30 \%$ for a mooring line aligned with the wind and wave direction, and between a 10 to $20 \%$ for the non-aligned mooring lines.

The stiffness of the mooring system is found to affect on the total damage of the lines. Stiffer mooring system will lead to an increase of the number of tension cycles of the mooring lines in the low frequency range, which will reduce its life span. A more detailed study on this parameter is needed to assess its behavior, because too compliant systems could lead to non-desirable motions and a lack of yaw stiffness for Spar platforms. Also the use of TM curves instead of SN curves for the fatigue analysis could help to account to the differences in the mean tensions of the lines and reduce the gap between the results.

The quasi-dynamic and quasi-static mooring models are used and compared with the dynamic mooring line model. It is found that for fairleads close to the CM of the platform, both models could be appropriate for the fatigue assessment, with the additional advantage of a limited computational time. For fairleads locations away from the $\mathrm{CM}$, the simplified models are less accurate. However, the quasi-dynamic response fits much better in the wave frequency range than the quasi-static approach.

\section{ACKNOWLEDGEMENTS}

The research leading to these results has received funding from the European Union's Horizon 2020 research and innovation programme under grant agreement No. 815083 (CoReWind).

\section{REFERENCES}

[1] M. V. O. W. A/S, "Innovations | Offshore Wind Turbines | MHI "Vestas." http://www.mhivestasoffshore.com/innovations/ (accessed May 02, 2017).

[2] G. R. ENERGY, "HALIADE-X OFFSHORE TURBINE.".

[3] E. Gaertner, J. Rinker, L. Sethuraman, F. Zahle, B. Anderson, G. Barter, N. Abbas, F. Meng, P. Bortolotti, W. Skrzypinski, G. Scott, R. Feil, H. Bredmose, K. Dykes, M. Shields, C. Allen, and A. Viselli, "Definition of the IEA 15-Megawatt Offshore Reference Wind," Golden, CO.

[4] E. W. C. Wilkins, "Cumulative damage in fatigue," in Colloquium on Fatigue / Colloque de Fatigue / Kolloquium über Ermüdungsfestigkeit, Berlin, Heidelberg: Springer Berlin Heidelberg, 1956, pp. 321332.

[5] D. L. Garrett, "Dynamic Analysis of Slender Rods," $J$. Energy Resour. Technol., vol. 104, no. 4, pp. 302-306, 1982, doi: 10.1115/1.3230419.

[6] J. Palm, C. Eskilsson, and L. Bergdahl, "An hp-adaptive discontinuous Galerkin method for modelling snap loads in mooring cables," Ocean Eng., vol. 144, no. August, pp. 266-276, 2017, doi: 10.1016/j.oceaneng.2017.08.041.

[7] P. Trubat and C. Molins, "Rheological damping of slender rods," Mar. Struct., vol. 67, 2019, doi: 10.1016/j.marstruc.2019.102639.

[8] O. M. Aamo and T. I. Fossen, "Finite element modelling of mooring lines," Math. Comput. Simul., vol. 53, no. July, pp. 415-422, 2000, doi: 10.1080/10473289.2011.636501.

[9] P. Trubat, "Station keeping analysis and design for new floating offshore wind turbines," Universitat Politècnica de Catalunya - BarcelonaTech, 2020.

[10] S. Chakrabarti, Handbook of Offshore Engineering, vol. I. Elsevier, 2005.

[11] A. Campos, C. Molins, X. Gironella, and P. Trubat, "Spar concrete monolithic design for offshore wind turbines," Proc. Inst. Civ. Eng. - Marit. Eng., vol. 169, no. 2, pp. 49-63, Jun. 2016, doi: 10.1680/jmaen.2014.24.

[12] P. Trubat, J. Bairan, A. Yagüe, and C. Molins, "Windcrete fatigue verification," in ASME 2019 2nd International Offshore Wind Technical Conference, IOWTC 2019, 2019, pp. 1-8, doi: 10.1115/IOWTC20197564.

[13] F. Vigara, L. Cerdán, R. Durán, S. Muñoz, M. Lynch, S. Doole, C. Molins, P. Trubat, and R. Guanche, "D1.2 
Design Basis,” 2019.

[14] M. Y. Mahfouz, M. Salari, S. Hernández, F. Vigara, C. Molins, and P. Trubat, "D1.3 Public design and FAST models of the two 15MW floater-turbine concepts,"
2020.

[15] NREL, "OpenFAST Documentation.”. 